\title{
How does Canada's health system compare?
}

A New York-based research foundation is disputing the Fraser Institute's recent conclusions that Canada's health care system does not perform well when compared to other OECD countries.

Members of The Commonwealth Fund, a private, nonprofit research group, claim performance indicators they have just developed are more accurate than those the Institute used, and show that Canada's system has strengths as well as weaknesses.

"The old indicators are a very $\vec{\infty}$ poor way of comparing health care system performance," said Dr. John Millar, a Canadian representative to the Fund. "Something like life expectancy is influenced by economic performance and educational background. It reflects what is going on in the broader society," adds Millar, executive director of the Provincial Health Services Authority in BC.

In May, the Fraser Institute, a conservative think-tank, released a study comparing Canada to 23 OECD countries and concluded Canada doesn't get enough bang for its buck and lacks ready access to physicians and technology. In terms of physician supply, Canada ranks 16th, with 2.3 doctors per 1000 people.

The Fraser Institute used the statistics to argue the need for a private parallel health care system. "If we permitted cost sharing, allowing Canada to have private competitive hospitals, we would likely have better health outcomes." said Nadeem Esmail, senior health analyst.

The Fraser Institute study used 7 outcome measures to rank Canada's performance.

The Fund's study (Health Affairs 2004;23 [3]:89-99), released in May, compared health care quality data on 21 indicators (including survival rates for 9 conditions) in 5 countries (Australia, Canada, England, New Zealand and the US).

It found that every country ranks both worst and best on at least one measure. Canada had the highest 5-year survival for childhood leukemia and for kidney and liver transplants. It also had the highest acute myocardial infarction 30-day case fatality rates.

Overall, the study concludes Americans are getting the poorest value for their monetary investment. - Louise Gagnon, Ottawa

\section{Women's Health}

\section{Emergency contraception could lower abortion rate}

Anti-abortion groups should welcome proposed new regulation allowing patients to access emergency contraception without a prescription, says the Society of Obstetricians and Gynaecologists of Canada.

"Whatever you believe, it's better to prevent an unwanted pregnancy than have an abortion," executive vice-president Dr. André Lalonde told CMAF.

In Canada, about $25 \%$ of all pregnancies (approximately $109500)$ end in abortion each year. According to 2001 Statistics Canada figures, emergency contraception has the potential to prevent 106418 abortions (including 19936 among teenagers) annually. The US predicts it could halve demand.

"If you're against abortion, this is a wonderful pill," says Lalonde.

Emergency contraception, or the "morning after pill," is sold in Canada as levonorgestrel (Plan B). If taken within 72 hours of unprotected intercourse, it can prevent ovulation, or interfere with fertilization, or implantation. Levonorgestrel is available without prescription in 31 countries and 5 US states.

The Catholic Organization for Life and Family and other anti-abortion groups believe pregnancy begins with conception, not implantation. In a letter to Health Canada, the organization called levonorgestrel an "abortifacient."

On May 18, the federal government announced it is amending regulations to make levonorgestrel a "behind-thecounter" product, available after consulting with a pharmacist. Stakeholders will have until mid-August to comment on the change, which should take effect this fall.

The Canadian Pharmacists Association is providing a minicourse for pharmacists on dispensing the drug. Levonorgestrel is already available behind-thecounter in BC, Quebec and Saskatchewan.

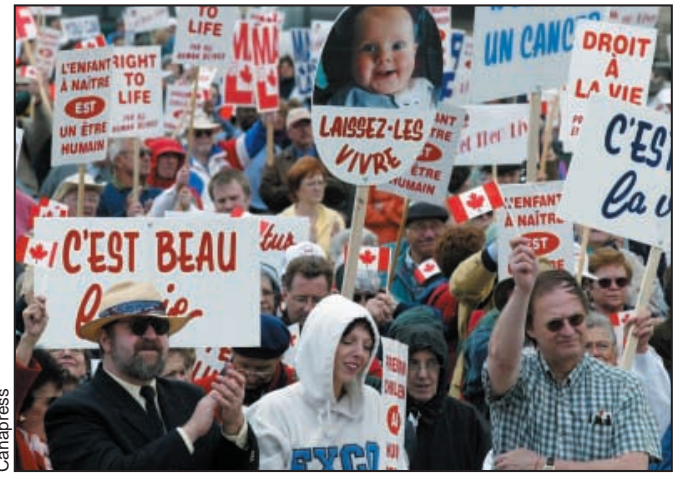

Past tense? Easily accessible emergency contraception could eliminate the need for $50 \%$ or more abortions.

Days before Canada's announcement, the US Food and Drug Administration ignored the recommendations of its scientific advisers and refused to make emergency contraception available without a prescription. The American College of Obstetricians and Gynecologists called the decision "a dark stain on the reputation of any evidence-based agency like the FDA." - Barbara Sibbald, CMAJ 